\title{
Embedding reflexivity within experiential qualitative psychology
}

Rachel L Shaw, PhD, CPsychol

Lecturer in Psychology, School of Life and Health Sciences, Aston University,

Birmingham, B4 7ET, UK. Tel: +44(0)121 2044050; Fax: +44(0)121 2044090;

Email: r.l.shaw@aston.ac.uk.

\begin{abstract}
In this article, it is argued that reflexivity is integral to experiential qualitative research in psychology. Reflexivity has been defined in many ways. Woolgar's continuum of reflexivity though provides a useful gauge by which to judge whether a researcher is involved in simple reflection or reflexivity. The article demonstrates the benefits of adopting a reflexive attitude by presenting "challenge-to-competency." The author's encounter with Sarah will help illustrate the role of reflexivity both in data generation and in interpretative analysis. To close, it is proposed that reflexivity as hermeneutic reflection, with its grounding in hermeneutics and phenomenology, is a useful construct for guiding our engagement in reflexivity in experiential qualitative research.
\end{abstract}

\section{Keywords}

Reflexivity, phenomenology, hermeneutics, interpretative phenomenological analysis.

Final version of published paper: Shaw, R.L. (2010). Embedding reflexivity within experiential qualitative psychology. Qualitative Research in Psychology, 7(3), 233243. 


\section{Embedding reflexivity within experiential qualitative psychology}

Most qualitative researchers are familiar with the notion of reflexivity and arguments in favour of engaging with it. Put simply, when the researcher and researched are of the same order, that is, both living, experiencing human beings, it is necessary for us as researchers to reflect on how that might impact the research scenario when gathering data and when afterwards analysing it. For the majority of qualitative researchers, data gathering involves engaging with other people’s language, the stories they tell and/or the experiences they have. Our job as researchers is to make sense of these stories and experiences in a meaningful way with a view to learning more about humankind and, often, to effect change, whether that be in terms of influencing policy and practice or enhancing understanding at an individual or institutional level.

With this task comes responsibility and for some that alone is sufficient to necessitate reflexivity. In this paper, I will develop the argument for embedding reflexivity within experiential qualitative research in psychology by using an example from my own empirical work.

\section{The place of reflexivity in experiential qualitative psychology}

Reflexivity has been defined in a variety of ways; the differences in definition largely depend on the philosophical or pragmatic approach adopted by the writer. In The reflexive thesis, Ashmore (1989) explores the ‘problem’ of reflexivity and the different mechanisms (both philosophical and pragmatic) for dealing with it from the perspective of the sociology of scientific knowledge. Gergen (1973) also refers to the Final version of published paper: Shaw, R.L. (2010). Embedding reflexivity within experiential qualitative psychology. Qualitative Research in Psychology, 7(3), 233243. 
potential threat of reflexivity, described as 'feedback and static' within the research scenario. Others have focused on critical approaches to psychology by emphasising social constructions of the Other and the process of Othering when conducting research with people (Wilkinson and Kitzinger, 1996). To begin our reflexive journey, Woolgar's (1988) identification of a continuum of reflexivity is particularly useful; he describes this continuum as ranging from radical constitutive reflexivity to benign introspection (or reflection). The theory behind this may also help answer the question many people ask: 'what is the difference between reflection and reflexivity?'

Qualitative researchers are familiar with the essentialism of the natural sciences - the positivist position which maintains a fixed, objective reality that is 'out there' to be discovered and that is a separate entity from those who inhabit the world. Moreover, positivism assumes an unproblematic, straightforward relationship between an object in the world and the way in which we talk about it (or represent it). Qualitative researchers working in an interpretivist paradigm deny objectivity and instead focus on the intersubjective realm; that is, what happens in the interactions between us and our world, the context in which we come into contact with objects (reality) and the way in which our descriptions (representations) of them are bound by time and place. In other words, reality is fluid and constituted in and of the moment as it is lived. This means that the relationship between objects in the world and those who live in that world is no longer one of separateness: "representation and object are not distinct, they are intimately interconnected” (Woolgar, 1988: 20).

At one extreme of Woolgar's continuum we have benign introspection - or reflection - which maintains a positivist distinction between object and representation and thereby aims to present an 'accurate' representation of participants' accounts. At the Final version of published paper: Shaw, R.L. (2010). Embedding reflexivity within experiential qualitative psychology. Qualitative Research in Psychology, 7(3), 233243. 
other extreme, we have radical constitutive reflexivity which takes the postmodern stance that reality is constructed contemporaneously and no account (whether the researcher's or the participant's) can be valued over another. What separates reflexivity from reflection, from Woolgar's perspective, is that reflection is a more general set of thoughts concerned largely with process and verification, ensuring that measures are taken to represent participants in their 'true' light. In other words, reflection often aims to achieve the positivist goal of accuracy when reporting participants' accounts of reality. This is often considered as a discrete set of tasks to ensure quality (Hammersley \& Atkinson, 1995). Reflexivity, on the other hand, is an explicit evaluation of the self. From its etymological roots, we know that 're-flexivity' involves looking again, turning your gaze to the self; in effect, reflexivity involves reflecting your thinking back to yourself. It evokes an interpretivist ontology which construes people and the world as interrelated and engaged in a dialogic relationship that constructs (multiple versions of) reality. A reflexive study will therefore assume the co-constitution of meaning within a socially oriented research scenario. It is argued that taking a reflexive attitude enables a holistic approach to psychological research which is imperative for it to address the implications of the researcher and researched being of the same order. Thus, reflexivity must be embedded within experiential qualitative psychology.

There are further arguments to support the integration of a reflexive attitude into experiential qualitative psychology. Firstly, as social beings, our experiences must be understood within the context in which they happen; the ways in which we make sense of our experiences and ourselves are bound by time and place. Our intricate link to the social world in which we live is demonstrated by Brentano's (1995) notion of Final version of published paper: Shaw, R.L. (2010). Embedding reflexivity within experiential qualitative psychology. Qualitative Research in Psychology, 7(3), 233243. 
intentionality: as human beings interacting with the world, we are not simply conscious but are conscious of things. In other words, when we walk into a room and encounter an object that seems appropriate for sitting on, we are not simply aware of the object's presence in the room, we are aware of it as a chair and that its purpose is for sitting on. Moreover, we can discern what sort of function the chair has by its design; a soft furnished 'easy' chair by a fireplace is for relaxation while an upright chair on wheels next to a PC terminal is meant for work. This indicates our embeddedness within our culture - a westernised culture where activities take place indoors and work is separate from leisure. Heidegger's existential phenomenology and his focus on Dasein - being-in-the-world - also brings to the fore our inextricable link to the world in which we live and its impact on what it means to be human. As Palmer reminds us, in the "historicality and temporality, he saw clues to the nature of being” (Palmer, 1969: 125). Indeed, Heidegger (1962) argued that when we encounter new things, we experience them as already interpreted. In short, meaning-making is at the core of human experience; we are endowed with agency and the ability to actively make sense of our experiences and each other (Bruner, 1990) but we do this within the constraints of the world in which we live.

Secondly, an implication of our social situatedness is that we experience and interpret the world from a particular perspective and we can never fully escape this subjectivity. Gadamer (1975) spoke of this in terms of horizons; we each have our own presuppositions, beliefs, predilections and these make up our own horizon (or sphere) of understanding. When we meet another person, if our two horizons overlap (like two circles in a Venn diagram), then we will be able to make ourselves understood and in turn understand the other person. For Gadamer, this fusion of Final version of published paper: Shaw, R.L. (2010). Embedding reflexivity within experiential qualitative psychology. Qualitative Research in Psychology, 7(3), 233243. 
horizons is effected by first making ourselves more transparent. Finlay (2003: 108)

further clarifies Gadamer’s theory:

“Our understanding of 'other-ness' arises through a process of making ourselves more transparent. Without examining ourselves we run the risk of letting our unelucidated prejudices dominate our research. New understanding emerges from a complex dialectic between knower and known; between the researcher's past pre-understandings and the present research process, between the selfinterpreted co-constructions of both participant and researcher. Between and beyond...”

Gadamer's horizons, together with Heidegger's being-in-the-world, provide further support for adopting a reflexive approach in experiential qualitative research. Through making ourselves aware of our own feelings about and expectations of the research we can begin to fully appreciate the nature of our investigation, its relationship to us personally and professionally, and our relationship as a researcher and experiencer in the world to those with whom we wish to gather experiential data. By engaging in reflexivity, that is, proactively exploring our self at the start of our research inquiry, we can enter into a dialogue with participants and use each participant's presentation of self to help revise our fore-understanding and come to make sense of the phenomenon anew.

\section{Doing reflexivity in an interpretative phenomenological study}

What follows is an example which illustrates the role of reflexivity in experiential qualitative research in psychology. In this study I interviewed young mothers and analysed their data using interpretative phenomenological analysis (IPA; Smith and Eatough, 2007). IPA is grounded within hermeneutics and phenomenology. It aims to understand individuals' experiences and how individuals make sense of their experiences by gaining an ‘insider’s perspective’ (Condrad, 1988). In line with

Final version of published paper: Shaw, R.L. (2010). Embedding reflexivity within experiential qualitative psychology. Qualitative Research in Psychology, 7(3), 233243. 
Gadamer's notion of horizons, IPA recognises the significance of the researcher's presuppositions and that they can both hinder and enhance the interpretation of another's lived experience. The resultant dialogue between the researcher and researched is described as a double hermeneutic:

"the participants are trying to make sense of their world; the researcher is trying to make sense of the participants trying to make sense of their world" (Smith and Osborn, 2008: 53)

This layering of interpretative processes demonstrates the complexity within the intersubjective realm in which experiential qualitative research is conducted. In this double hermeneutic which has particular relevance for IPA research, we find further support for adopting a reflexive attitude in which self and other - and the relationship between them - are explicitly examined as part of the research process.

This example follows the story of my relationship with a young woman, Sarah, who had her first child at the age of sixteen. The study aimed to investigate young women's decision-making processes and beliefs about infant feeding (Shaw, Bansal \& Wallace, 2003). As women under 20 years of age living in low socio-economic areas of Britain they were among those least likely to breastfeed; the project had a health promotion objective of exploring these women's understanding of breastfeeding in order to encourage more of them to choose this method of feeding. Sarah and the other women in the sample were interviewed antenatally and twice following the birth of their baby. This reflexive account focuses on an incident in my third interview with Sarah. Some of what will be presented results from reflective notes made immediately following the interview but other aspects are retrospective. Through revealing my own 'challenge-to-competency' I intend to illustrate, with the Final version of published paper: Shaw, R.L. (2010). Embedding reflexivity within experiential qualitative psychology. Qualitative Research in Psychology, 7(3), 233243. 
benefit of hindsight, the value of taking a reflexive approach to interviewing in experiential qualitative research. I will then consider the impact of reflexivity in the analysis as well as implications for publication.

When we read about qualitative interviewing techniques, writers often emphasise the need to establish a rapport with participants (e.g., Robson, 2002; Kvale, 1996; Smith, 1995) but as someone who regularly says this to students, I realise how difficult it is to explain how actually to go about it. In my meetings with Sarah, both before she had the baby and afterwards, she mentioned her education. This was a perfect opportunity for me to bond with Sarah because, as a postdoctorate research associate (at the time) who had gone straight from A levels to undergraduate and postgraduate study with a view to establishing an academic career, education was (and is) clearly important to me.

Before the birth, Sarah's focus was to complete her GCSEs but her due date was in the middle of the exam period. Sarah moved to a school run especially for young pregnant women enabling her to easily take time out for hospital visits and to choose where she sat her exams, at school, home or in hospital. The next time I saw Sarah she had not yet received her exam results but was planning to go to college if she achieved the requisite grades. Then when I met Sarah for the last time she had started college and was proud to show me the work she had completed for her Art GCSE, her favourite subject. This appealed to me because I too had enjoyed GCSE Art and had done many similar projects, so felt I at least had that very basic level of shared experience. Just as we started the interview, Sarah changed her baby’s nappy and while she was doing this I asked how she was doing at college: Final version of published paper: Shaw, R.L. (2010). Embedding reflexivity within experiential qualitative psychology. Qualitative Research in Psychology, 7(3), 233243. 
Rachel: How's it going?

Sarah: I haven't been since last week. All last week. Because I've been having time off because [indecipherable]. And one of my college friends phoned up and said 'why haven't you been in college?' but I've had to go to hospital. What day is it today?

Rachel: It's Tuesday.

Sarah: It was last Wednesday.

Rachel: Yeah.

Sarah: I'm on the pill but I fell pregnant and I didn't know.

Rachel: [intake of breath]

Sarah: And apparently I was 3 months and she's only blooming 5 months, not even that.

Rachel: Oh my god!

Sarah: But I've miscarried it anyway.

Rachel: I bet that was a bit of a shock.

Sarah: One minute I said what? No. No I couldn't. She put me on the high pill as well. I thought oh no. I'm having the injections as well now.

Clearly, this exchange is problematic. Always preferring an optimistic view, I could argue that this extract demonstrates my success in building a rapport with Sarah - she had felt comfortable enough to share with me a potentially traumatic event.

Notwithstanding this, what I then did undermined that trusting relationship. I was evidently shocked and could find no words to respond to Sarah's initial statement. Not yet having formulated an 'appropriate' response, Sarah then revealed that she had miscarried this pregnancy. In a few short seconds, what seemed to me to be a naïve and somewhat foolish mistake - to accidentally get pregnant a second time so soon after conceiving unplanned the first time - mutated into a potentially distressing turn of events. There are several aspects of this exchange worthy of discussion which highlight the benefit of taking an actively reflexive approach to interviewing.

\section{Constitutive reflexivity in-the-moment of data generation}

Sarah seemed to inhabit a very different world from the one I had known at sixteen which is why I was surprised to find Sarah and I had something in common; our Final version of published paper: Shaw, R.L. (2010). Embedding reflexivity within experiential qualitative psychology. Qualitative Research in Psychology, 7(3), 233243. 
GCSE Art. Raised in a religious, white collar household with an older brother who had already gone to university, my family ethic was to succeed at school, go to university and get a good job. To leave education would have been considered a failure and to fall pregnant at that age out of wedlock would have been considered a shameful and ruinous act. This may be a cultural cliché that overemphasises the moralistic proclivities of a family like mine (rather than the 'reality' of how my family would have actually reacted to my being pregnant at sixteen); nevertheless it is this salient aspect of my cultural history - my horizon - which helped construct my fore-understanding of teenage pregnancy. In the absence of any self-analysis prior to embarking on this project, these issues were latent and therefore ready to appear in a research encounter given an appropriate trigger, such as occurred in my interview with Sarah.

This fore-understanding was not just a product of my family; the pseudo-religious moral codes espoused by both religious and secular institutions (such as the church, the government, schools and general practice surgeries) also played a role. As such, the wider social, historical and cultural context gathered force for this judgemental and prejudiced - view of teenage pregnancy. As an early career researcher, I believed that my psychological training and previous research experience would enable me to establish a rational distance between this subjective personal history and the pursuit of scientific knowledge. Instead, the scientific realm added another layer to the formation of my fore-understanding; science itself has framed teenage pregnancy as a negative phenomenon. The majority of teenage mothers in the UK have low socioeconomic status and are therefore considered to face health inequalities.

Consequently, the children of young, socio-economically deprived women are likely Final version of published paper: Shaw, R.L. (2010). Embedding reflexivity within experiential qualitative psychology. Qualitative Research in Psychology, 7(3), 233243. 
to be more at risk than the general population. It is now the government's objective to reduce such inequalities in order to create a 'healthier nation'. Thus, one could argue that young women who fall pregnant are jeopardising the country’s future health. Working in the area of breastfeeding promotion, it was difficult to rid the need to educate those facing inequalities from the patronising tone that infiltrates that quest. It presupposes that the experts - in this case academics and health professionals - need to share their 'wisdom' with the less well educated (or less fortunate) in order to bring them up to an acceptable level of knowledge. While I understand and agree with health education, the patronising undertones of this assumed superiority make me feel uncomfortable. Nevertheless, a negative judgement of teenage pregnancy based on education was clearly sanctioned by both the government and academic community in a way that a judgement based on religion or moral codes was not. At the time, I had not made myself aware of or considered the potential impact of these layered connotations of teenage pregnancy on my meetings with young pregnant women. Consequently, I was unable to pre-empt this somewhat judgemental response to Sarah’s news of a second unplanned conception so soon after the first one.

Each of the issues discussed thus far reflect my cultural and historical situatedness and its relationship to my performance as a person doing research with people. The challenge of reflexivity for an experiential qualitative researcher is to first identify these fore-understandings and their routes and then to ensure they do not denigrate the research process, either in terms of the social event that is the research interview or the interpretative activity of analysing experiential data. It is evident in the extract from my interview with Sarah that I had not set out on a reflexive footing. Although aware at some level of these constructs being at work in my mode of thinking, I was Final version of published paper: Shaw, R.L. (2010). Embedding reflexivity within experiential qualitative psychology. Qualitative Research in Psychology, 7(3), 233243. 
not self-consciously aware of them in a way that made them explicit. To be reflexive, we need to reveal our presuppositions in order to not be surprised by them (or what they do) anymore; these presuppositions remained latent and therefore still potent when faced with a powerful enough emotive trigger. By engaging reflexively with these fore-understandings and making them explicit in advance of data gathering, we are able to work actively with them in a research encounter. This will not lead to the 'perfect' research interview (which does not exist) but with practice, it will provide mechanisms for avoiding unguarded responses to surprises like Sarah’s.

The final point I want to make about this extract concerns my assumption that Sarah's miscarriage was distressing. My “Oh my god!” response is clearly inappropriate and functioned as a filler as well as an exclamation; I had no idea how to react to this statement. However, if we look closely at what Sarah says ("But I've miscarried it anyway.”), she presents this eventuality as a relief; later she says she does want other children but was certainly not planning to have any so soon. To this day I am unsure how Sarah made sense of her miscarriage because I did not give her the opportunity to talk about it. A few lines after the extract above ended I directed our conversation back to our/my comfort zone - education. This could have been a welcome change of subject for Sarah. It certainly was for me. In fact, re-directing the focus in this way enabled me to re-exert my power, power that I had lost through my 'challenge-tocompetency'. Equally, though, Sarah may have welcomed the opportunity to reflect out loud about this experience in a way that may have helped her come to terms with it. This demonstrates how a lack of awareness can detract focus from the participant's experience thus potentially losing richness from the account. This is obviously detrimental to an experiential study but may also be questioned ethically, in that it Final version of published paper: Shaw, R.L. (2010). Embedding reflexivity within experiential qualitative psychology. Qualitative Research in Psychology, 7(3), 233243. 
may leave potentially distressing experiences or memories unexplored, which could make participants vulnerable in a way that they were not before the interview. For many, this would be a particularly powerful argument in favour of reflexivity in such an in-depth experiential pursuit.

Reflexivity is not simply an awareness-raising activity that we engage in prior to and during data collection. It is a vital component of each stage of the research journey. As we have seen, understanding is not something locked inside our heads but is borne out of our interactions with the world in which we live. In the small scale context of a research interview this means that both the time and place in which the interview happens and the relationship between interviewer and interviewee are each significant to us as qualitative analysts.

\section{Building impressions of Sarah as she appeared to me during analysis}

The openness toward the active role played by the analyst in IPA represents an inherently reflexive attitude. This is particularly significant in IPA (although I would argue it is important in any qualitative analysis) because interpretation plays such a central role. Engaging in reflexivity during analysis helps us to navigate our way through the participant's account and our responses to it. In thinking through our reactions in this way we can bring to the fore our assumptions and the mechanisms which construct those assumptions. This often involves revisiting the data and our reflective log at several points during the process. Sometimes an analyst needs distance in order to let an emotive response subside; at other times it is worth seeking another perspective from someone thus far uninvolved.

Final version of published paper: Shaw, R.L. (2010). Embedding reflexivity within experiential qualitative psychology. Qualitative Research in Psychology, 7(3), 233243. 
Returning to my encounter with Sarah, it is possible to see how the reflexive work following the interview helped guide my analysis. Sarah's story is full of contrasts: I found Sarah to be a strong, independent woman but she was also naïve and impressionable. Sarah was determined to initiate breastfeeding because she understood it to have health benefits for her baby and having arrived in her position (albeit unexpectedly) she wanted to be the best mother she could be in the circumstances. She was also adamant that she gain qualifications in order to provide for her child in the future. Sarah’s autonomy and sensible outlook appealed to me because I value these qualities in my own life. Nevertheless, on the surface she appeared to be naïve because of her quick change of heart in hospital ("I was going to breastfeed but, I’ve seen this woman opposite my bed. She was breastfeeding and she was screaming and I thought 'oh no'. So that put me off.”) and her second 'accidental' pregnancy. Having returned to this assumption during analysis I soon realised that Sarah's actions were far more complex. The lack of empathy in my initial judgement is clear: had I experienced childbirth and witnessed a breastfeeding experience such pain I would certainly think differently about Sarah's decision not to breastfeed; furthermore, contraception use is pretty sporadic across demographic groups with the number of 'unplanned pregnancies' far outweighing any that might be considered planned.

Taking the time to think through the mechanisms informing my judgement helped me see passed them and informed my impression of Sarah. The moralisation of teenage pregnancy could be construed as a legacy of the dominance of religion in shaping our cultural codes and practices; religion also played a particularly powerful role in my formative years. Nowadays, the stigma of childbearing out of wedlock has been Final version of published paper: Shaw, R.L. (2010). Embedding reflexivity within experiential qualitative psychology. Qualitative Research in Psychology, 7(3), 233243. 
replaced by the politicised concept of teenage pregnancy; furthermore, my remit as a health researcher was aligned with the government's target to reduce teenage pregnancy. This means that as a teenage mother interacting with the academic community, Sarah has to work to present an outwardly good self to the world; the tide is against her and so performing as a good mother is an almost insurmountable task. Being reflexive in this case meant confronting the prejudices of my response, interrogating them, moving beyond them and subsequently incorporating them into my understanding of Sarah’s lived experience.

Unfortunately there is no detailed write-up of my analysis of Sarah’s experiential account. The paper that was published (Shaw et al, 2003) presented themes across the whole sample of young mothers as well as the results of focus groups with health professionals. It was written for health professionals and published in a professional journal. This meant there was neither room to present a nuanced analysis of Sarah's experience nor a reflexive account of my experience as a researcher. Consequently, providing this reflexive analysis enabled me to reach what the Americans call closure; I had unfinished business with Sarah and wanted to do her story justice.

To summarise, this empirical example has illustrated several ways in which reflexivity may have enhanced both the research experience and the conclusions drawn from the data. Crucially, it has demonstrated the significance of dynamism and interrelatedness within experiential qualitative research; the research process is comprised of the messiness of human relationships, history and culture from which it simply cannot escape. Hence, reflexivity offers a mechanism for identifying and experiential qualitative psychology. Qualitative Research in Psychology, 7(3), 233243. 
managing issues arising from the fusion of horizons we encounter in experiential qualitative research.

\section{Reflexivity as hermeneutic reflection}

Looking at an empirical example in this way helps to stress the significance of reflexivity because of the inescapable (yet creative and insightful) interpretative activity involved in people researching people. It also helps identify what we mean by reflexivity. Finlay’s (2003) hermeneutic reflection feels most appropriate because of its grounding in hermeneutics and phenomenological reflection. Due to the inescapable act of interpretation and the way in which new encounters impact our fore-understandings, it follows that, as researchers engaging with experiential data reflexively we are involved in the "process of continually reflecting upon our interpretations of both our experience and the phenomena being studied so as to move beyond the partiality of our previous understandings and our investment in particular research outcomes" (Finlay, 2003: 108; emphasis in original). In the discussions of my interaction with Sarah we saw that there was movement within and between our different vantage points - or horizons of experience - which both hindered and enhanced my performance as a researcher. Our shared experience of GCSE Art and a concern for education enabled us to look at the world through the same lens for a brief moment. This shared vision was short-lived however and was soon obscured by the many other disparities between us as living beings in the world. At almost ten years her senior, with qualifications, a salary and the independence and ambition that come with those things, my priorities were very different from the young woman who, unplanned, had entered the realm of motherhood and was now learning to care for her baby and become an independent person in her own right. (Since giving birth, Sarah Final version of published paper: Shaw, R.L. (2010). Embedding reflexivity within experiential qualitative psychology. Qualitative Research in Psychology, 7(3), 233243. 
had moved out of the family home and was living with her new partner and her baby.) As such, the mundane activities of our everyday lived experience were significantly different making it particularly challenging for us to understand each other.

Secondly, Finlay considers the significance of phenomenological reflection to the employment of reflexivity in experiential qualitative research. The objective of phenomenological reflection is "to effect a more direct contact with experience as lived” (van Manen, 1990: 78). Finlay follows Heidegger’s commitment to historicality and temporality which make it impossible for us to bracket our presuppositions enabling 'direct' access to our own and others' experience in essence. However, what she takes from van Manen is the principle that while direct access is impossible, reflection - in the phenomenological sense - can awaken us to those presuppositions making them manageable and therefore enabling us as researchers to deal with them in an a priori and self-conscious fashion. Hence, hermeneutic reflection aims to emphasise proactive self-reflection, i.e., reflexivity, to facilitate awareness both of the dynamic relationship between ourselves as researchers and our participants' data and also of the way in which our research encounters change our fore-understandings to bring a fresh understanding of the phenomenon we are investigating.

Finlay (2003) offers another way of thinking about this by referring to Sartre’s (1969) distinction between:

"(1) Unreflective consciousness (as such, i.e., pour soi) where the self is an active agent - taken up with living in the moment. At this level, our consciousness is outside the scope of our experience or is lost in the experiencing where we are forgetful of our own agency. (2) Reflective consciousness - here the self and experience can become the object of Final version of published paper: Shaw, R.L. (2010). Embedding reflexivity within experiential qualitative psychology. Qualitative Research in Psychology, 7(3), 233243. 
reflection. (3) Self-reflective consciousness - at this most reflexive level, the self becomes the aim of reflection.” (Finlay, 2003: 109).

As experiential qualitative researchers, I would argue that engaging at the level of reflective consciousness while sometimes venturing into the self-reflective would constitute a reflexive approach to research. As a researcher doing research with people, my objective is twofold: to proactively manage my self in my interactions with my participants and the world; and to actively explore how these encounters impact my pre-existing beliefs and knowledge - my fore-understandings - in order to understand afresh the phenomenon I am studying. We must be cautious however in our reflexive efforts not to let ourselves get carried away on this tide of reflexivity "to the extent that the analyst and the phenomenon disappear from view” (Gough, 2003: 22). We must remember that our goal is to understand the nature of human experience in the many and varied ways in which it is lived. Reflexivity, while paramount in making explicit our interpretative activities, should not be the objective of research; rather, reflexivity can be seen as a way of being, a way of researching that will make our explorations as experiential qualitative researchers even more successful and enlightening.

\section{Conclusion}

This endeavour has illustrated the significance of reflexivity within experiential qualitative research in psychology by revealing my own ‘challenge-to-competency’. I have demonstrated how a project which explores human experience benefits from, and even demands, reflexivity. Unanswered questions remain, however, which require further examination.

Final version of published paper: Shaw, R.L. (2010). Embedding reflexivity within experiential qualitative psychology. Qualitative Research in Psychology, 7(3), 233243. 
One aspect of reflexivity which induces anxiety in some researchers is what level of reflexive account, if any, should be included in written reports and journal articles. The current account is very different from an empirical paper because it demanded high level disclosure simply to build the argument. I would not expect an empirical paper to require such detail. One model is to include a separate section in which authors declare their position in relation to the research question and/or participants (e.g., Shaw, 2004; Finlay and Gough, 2003). There are limitations with this approach if the author does not later return to the implications of his/her position in the analysis or discussion. Integrating your reflexive analysis within the analysis may be a better way of demonstrating how the involvement of the researcher impacted on the research process. Most writers agree that transparency is central to producing a trustworthy empirical research report (e.g., Lincoln and Guba, 1985); providing rationale statements to indicate motivations for decisions in research design and inserting discussions of context - from the perspective of both the researcher and researched in the analysis and discussion will help elucidate the research process and indicate that a reflexive approach has been adopted. However, a decision is often made by the nature of the journal to which the manuscript is submitted; some journals are open to the employment and frank discussion of reflexivity while others are less so.

For the time being, we can conclude that engaging with reflexivity is a necessary yet complex task in experiential qualitative research. Travelling the road with Sarah one more time has enabled me to further my 'reflexivity quest'. With some distance now from my encounter with her, it has been possible to examine the process in some detail and in so doing provide an evidenced rationale for embedding reflexivity within experiential qualitative psychology.

Final version of published paper: Shaw, R.L. (2010). Embedding reflexivity within experiential qualitative psychology. Qualitative Research in Psychology, 7(3), 233243. 


\section{Acknowledgements}

I would like to thank Sarah for taking part in the initial research and providing the inspiration for this project. Thanks also to Kevin Wright, Michael Larkin and anonymous reviewers for their valuable comments on an earlier draft.

\section{References}

Ashmore, M. 1989: The reflexive thesis: wrighting the sociology of scientific knowledge. Chicago: The University of Chicago University Press.

Brentano, F. 1995: Descriptive psychology. Transl. B. Müller. London: Routledge.

Bruner, J. 1990: Acts of meaning. Cambridge, MA: Harvard University Press.

Conrad, P. 1987: The experience of illness: recent and new directions. Research in the Sociology of Health Care 6, 1-31.

Finlay, L. 2003: Through the looking glass: intersubjectivity and hermeneutic reflection. In Finlay, L. and Gough, B. (editors) Reflexivity: a practical guide for researchers in health and social sciences. Oxford: Blackwell Publishing.

Finlay, L. and Gough, B. (editors) 2003: Reflexivity: a practical guide for researchers in health and social sciences. Oxford: Blackwell Publishing.

Finlay, L. in press: A dance between the reduction and reflexivity: explicating the "phenomenological psychological attitude”. Journal of Phenomenological Psychology.

Gadamer, H-G.. 1975. Truth and method ( $2^{\text {nd }}$ revised edition published in 1996). London: Sheed and Ward.

Gergen, K. 1973: Social psychology as history. Journal of Personality and Social Psychology 26, 309320.

Giorgi, A. (editor) 1985: Phenomenological and psychological research. Pittsburgh, PA: Dusquesne University Press.

Giorgi, A. 1970: Psychology as a human science: a phenomenologically sensitive approach. New York: Harper and Row.

Giorgi, A. 1994: A phenomenological perspective on certain qualitative research methods. Journal of Phenomenological Psychology 25, 190-220.

Giorgi, A. and Giorgi, B. 2008: Phenomenology. In Smith, J.A. (editor) Qualitative psychology: a practical guide for research methods ( $2^{\text {nd }}$ edition). London: Sage.

Gough, B. 2003: Deconstructing reflexivity. In Finlay, L. and Gough, B. (editors) Reflexivity: a practical guide for researchers in health and social sciences. Oxford: Blackwell Publishing.

Hammersley, M. and Atkinson, P. 1995: Ethnography: principles in practice ( ${ }^{\text {nd }}$ edition). London: Routledge.

Heidegger, M. 1962: Being and time. Oxford: Blackwell (Original work published in 1927).

Kvale, S. 1996: InterViews: an introduction to qualitative research interviewing. Thousand Oaks, CA: Sage.

Langdridge, D. 2007: Phenomenological psychology: theory, research and method. London: Pearson Prentice Hall.

Lincoln, Y.S. and Guba, E.G. 1985: Naturalistic inquiry. Newbury Park, CA: Sage.

Mishler, E.G. 1986: Research interviewing: context and narrative. Cambridge, MA: Harvard University Press.

Moran, D. 2000: Introduction to phenomenology. London: Routledge.

Palmer, R.E. 1969: Hermeneutics: interpretation theory in Schleiermacher, Dilthey, Heidegger, and Gadamer. Evanston: Northwestern University Press.

Robson, C. 2002: Real world research: a resource for social scientists and practitioner-researchers ( $2^{\text {nd }}$ edition). Oxford: Blackwell Publishing.

Final version of published paper: Shaw, R.L. (2010). Embedding reflexivity within experiential qualitative psychology. Qualitative Research in Psychology, 7(3), 233243. 
Sartre, J.-P. 1969: Being and nothingness. London: Routledge.

Shaw, R.L. 2004: Making sense of violence: a study of narrative meaning. Qualitative Research in Psychology 1, 131-151.

Shaw, R.L., Wallace, L.M. and Bansal, M. 2003: Is breast best? Perceptions of infant feeding. Community Practitioner 76, 299-303.

Smith, J.A. 1995: Semi-structured interviewing and qualitative analysis. In Smith, J.A., Harré, R. and van Langenhove, L. 1995: Rethinking methods in psychology. London: Sage.

Smith, J.A. 1996: Beyond the divide between cognition and discourse: using interpretative phenomenological analysis in health psychology. Psychology and Health 11, 261-271.

Smith, J.A. 2007: Hermeneutics, human sciences and health: linking theory and practice. International Journal of Qualitative Studies on Health and Well-being 3, 3-11.

Smith, J.A. and Eatough, V. 2006: Interpretative phenomenological analysis. In Breakwell, G., FifeSchaw, C. Hammond, S. and Smith, J.A. (editors) Research methods in psychology (3 ${ }^{\text {rd }}$ edition). London: Sage.

Smith, J.A. and Osborn, M. 2008: Interpretative phenomenological analysis. In Smith, J.A. (editor) Qualitative psychology: a practical guide to research methods ( $2^{\text {nd }}$ edition). London: Sage.

Smith, J.A., Harré, R. and van Langenhove, L. (editors) 1995: Rethinking psychology. London: Sage. van Manen, M. 1990: Researching lived experience: human science for an action sensitive pedagogy. New York: State University of New York Press.

Wilkinson, S. and Kitzinger, C. (editors) 1996: Representing the Other: a Feminism and Psychology reader. London: Sage.

Woolgar, S. 1988: Knowledge and reflexivity. London: Sage.

Final version of published paper: Shaw, R.L. (2010). Embedding reflexivity within experiential qualitative psychology. Qualitative Research in Psychology, 7(3), 233243. 